\title{
Further Investigation of the Effects of Font Styles on Perceived Visual Aesthetics of Website Interface Design
}

\author{
Ahamed Altaboli \\ Industrial and Manufacturing Systems Engineering Department, \\ University of Benghazi, Benghazi, Libya \\ Altaboli.UOB@gmail.com
}

\begin{abstract}
Findings of an earlier study indicated that a webpage using the "Times New Roman" font type was perceived as having better visual aesthetics than a webpage using the "Calibri" font type. The current study is a continuation of this research, the purpose of the study is to investigate how using a mixture of the two font types in the same webpage would affect perception of visual aesthetics. Four webpage designs were compared in the current study; the two designs used in the earlier study and another two designs containing a mixture of both fonts. Results showed that mixing the two font types on the same page didn't improve perception of visual aesthetics. Still, the webpage design with only the Times New Roman font type perceived as having a better visual aesthetics than all the other three designs.
\end{abstract}

Keywords: font style, font type, perceived visual aesthetics, website interface design.

\section{Introduction}

Most of font types used in printing and on screen belong to two font styles: serif and sans-serif. A "serif" is a French term for a short decorative line (edge) at the start or finish of a stroke in a letter, and "sans-serif" is a French term meaning "without-serif". i.e. the serif style has edges that project from the main letter block, while the sans-serif style doesn't have these edges.

The effect of each style on readability and legibility is one concern of the field of document, screen and interface design, finding of related studies mostly agree that on printed papers the serif style gives better readability and legibility than the sans-serif style [2], while; on a computer screen this advantage of the serif types is reduced, and findings of several studies indicated that the sans-serif types have more readability and legibility [2, 4, 5 and 8]. This is due to the fact that on computer screens each character is displayed as dot-matrix (or pixels), which results on the character with the edges "serif" appears jagged. This effect increases with low resolution of the screen and should be reduced with higher screen resolutions. As screen resolution increases this jagged effect should be eventually eliminated [2]. 
Other than the issues of readability and legibility, there is the issue of which font style would be more aesthetically appealing for the users and how it would affect the overall visual appeal and aesthetics of the interface. An earlier study [1] compared the effects of the two font styles (serif and sans-serif) on the overall perception of visual aesthetics of website interface design. Two font types were tests in this study, namely: "Time News Roman" representing the "serif" style and "Calibri" representing the "sans-serif" style. Results indicated that the design with the Time New Roman font (the serif style) was perceived as having better visual aesthetics than the design with the Calibri font (sans-serif style).

The current study is a continuation of this research, the purpose of the current study is to investigate how using a mixture of the two font styles and font types in the same webpage (compared to the single styles and types used in the earlier study) would affect perception of visual aesthetics of the page design.

Four webpage designs were compared in the current study; the two designs used in the earlier study (one with the Time News Roman font and one with the Calibri font), and another two designs containing a mixture of both fonts.

\section{$2 \quad$ Method}

\subsection{Design of the Experiment}

An experiment was designed and conducted to test the effects of font type on participants' perceived visual aesthetics of website design.

A one- factor (font type) within participants design was utilized with four levels associated with the four conditions to be tested. Four designs of a webpage were prepared to represent the four levels. All designs have identical formats (colors, menus ...etc); the only difference is the font type(s) used in each design; in one design the Times New Roman font type was used in all text in the webpage, in the second design the Calibri font type was used. The third and fourth designs used a mixture of both types; in the third, the Times New Roman font type was used in the main title and in the navigation bar and menus, while the Calibri font type was used only for the main text on the page. With the fourth design the two font types were exchanged; Calibri was used in the main title, the navigation bar and menus, and the Times New Roman font was used for the main text.

Screen shots of the four designs of the webpage are presented in Fig1 to Fig 4. The webpage represents a homepage of a hypothetical website that talks about the ancient history of a certain region of North Africa.

User perception of visual aesthetics was measured using the VisAWI (Visual Aesthetics of Website Inventory) questionnaire [7]. The instrument is based on four interrelated facets of perceived visual aesthetics of websites: simplicity, diversity, colorfulness, and craftsmanship. Simplicity comprises visual aesthetics aspects such as balance, unity, and clarity. The Diversity facet comprises visual complexity, dynamics, novelty, and creativity. The colorfulness facet represents aesthetic impressions perceived from the selection, placement, and combination of colors. Craftsmanship comprises the skilful and coherent integration of all relevant design dimensions. Each of the first two facets is presented by five items in the questionnaire, while each of the last two facets has four items. 
The font type(s) used in each design with its four conditions represents the independent variable. Questionnaire scores represent the dependent variable.

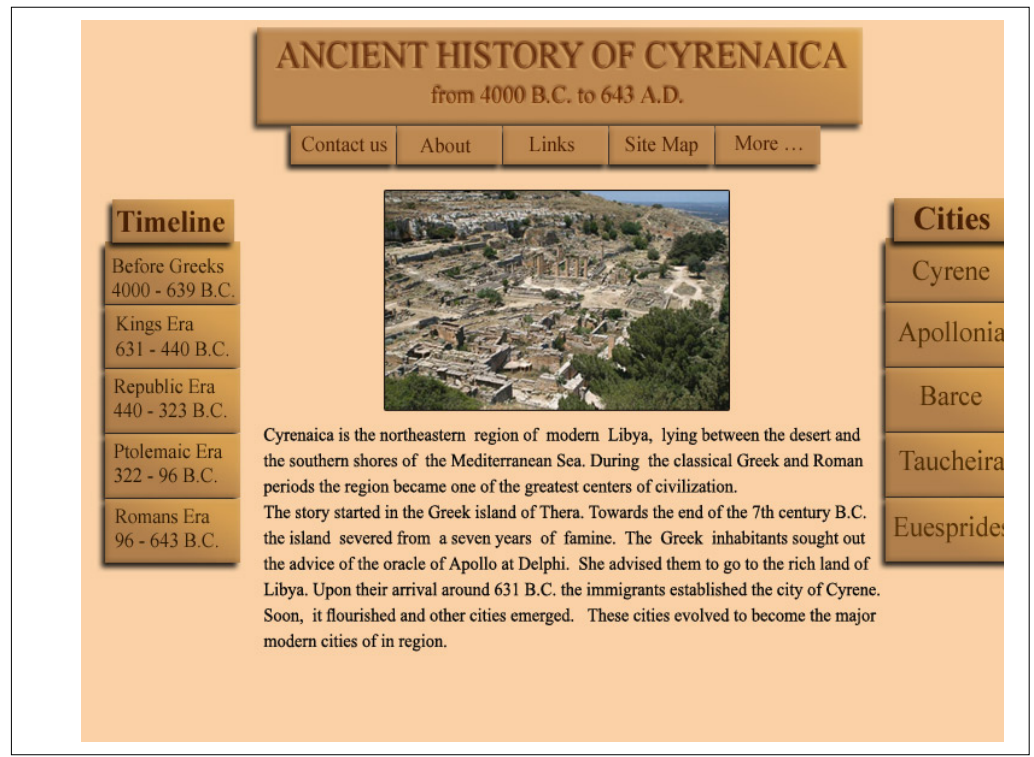

Fig. 1. Screen shot image The Times New Roman design

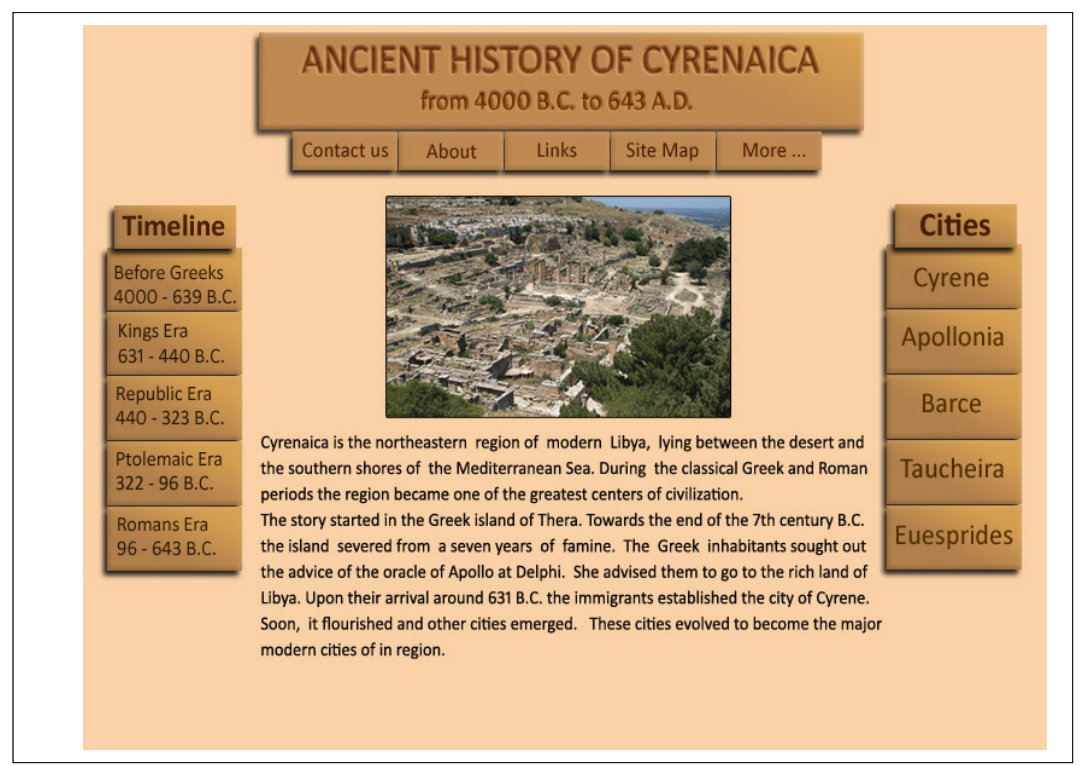

Fig. 2. Screen shot image the Calibri design 


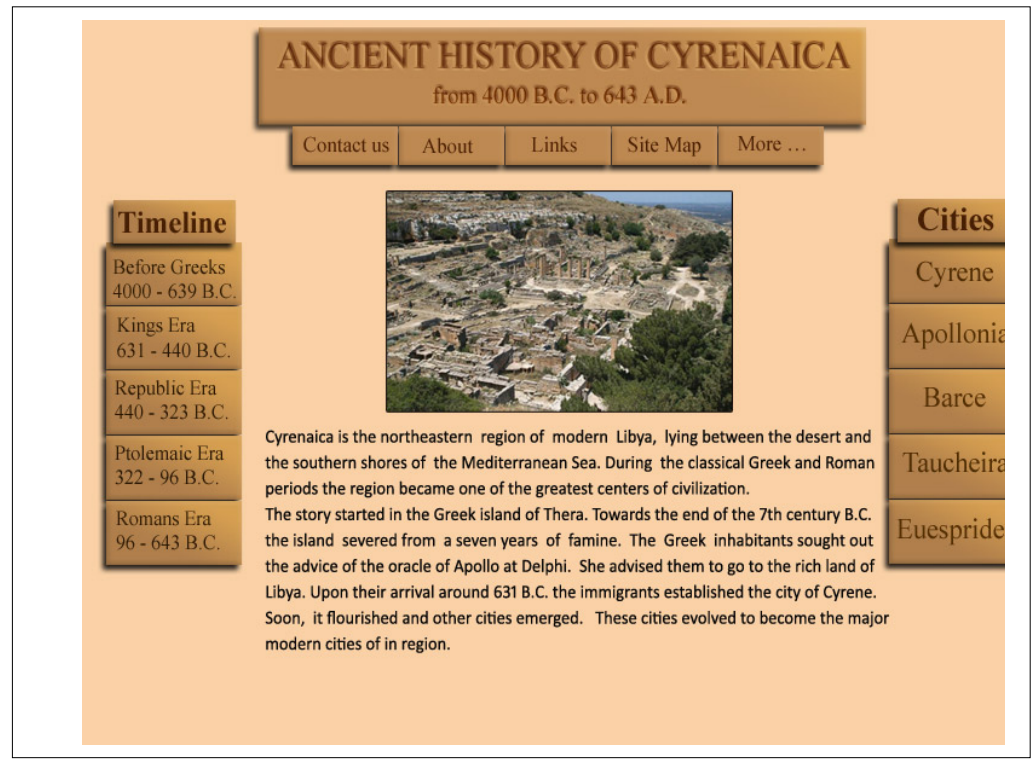

Fig. 3. Screen shot image of the Roman-Calibri design

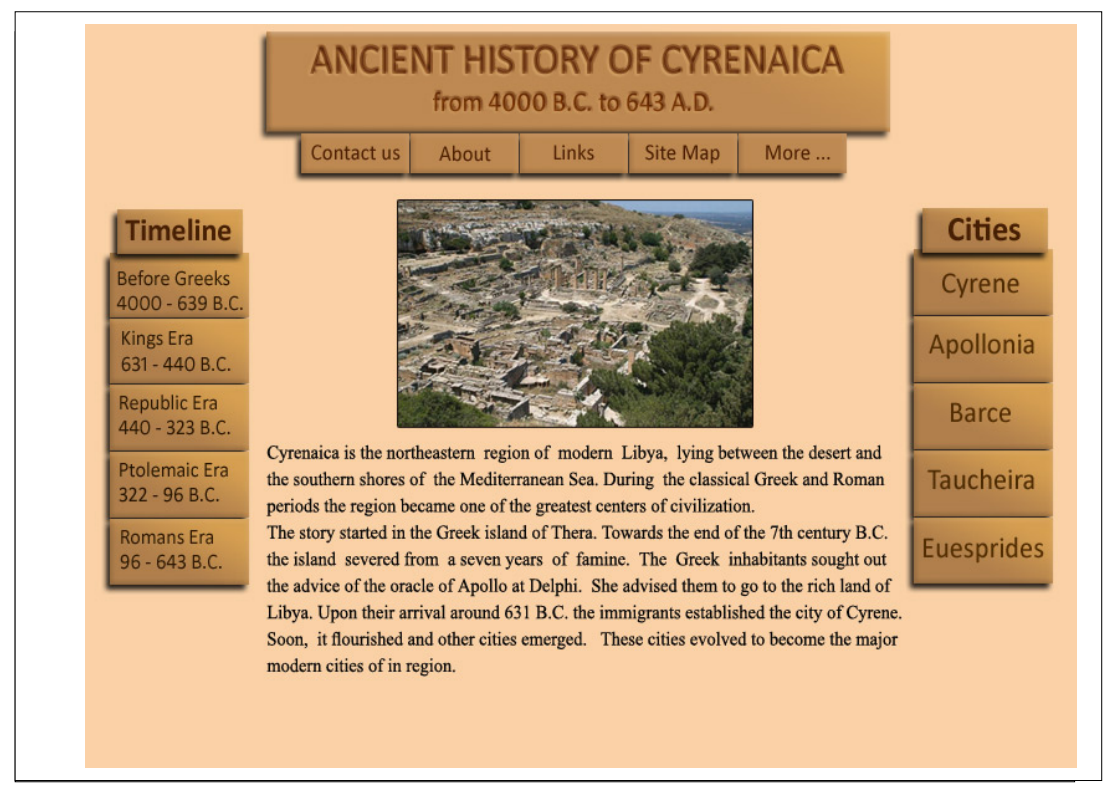

Fig. 4. Screen shot image of the Calibri-Roman design 


\subsection{Participants}

Participants were recruited online. Email invitations were sent to audience within the United States with the choice of entering a lottery to win 100 US dollars. A total of 56 responses were received, from which 32 were valid responses. Average age of participants with valid responses is 47.9 years with a standard deviation of 7.4 years. 13 were males and 19 were females.

\section{Results}

Images of screen shots of the four designs were presented to each participant one at a time with an on screen size of 800X600 pixels. The questionnaire was placed under each image. Each participant had to answer the questionnaire for each design using a seven-point Likert scale. Both images and questionnaire items were presented in random orders for each participant.

Table 1 summarizes average scores per each scale (aesthetic facet) and for the total score. The averages were presented per each design (Roman, Calibri and the mixed Roman-Calibri and Calibri-Roman ). Cronbach's $\alpha$ was used to measure reliability of the questionnaire. All calculated values were larger than 0.94 for the different scales of the questionnaire, indicating an acceptable level of reliability.

From the table it can be seen that with all scales and with the total, slightly higher average scores were recorded in the Roman design. However; the results of analysis of variance show that these differences are only significant with the craftsmanship scale and the total with p-values of 0.017 and 0.040 respectively. Pair-wise comparisons of average scores in both cases showed that the average score of the Roman design is significantly higher than the average scores of the other three designs. Participants perceived the Roman design as having better visual aesthetics than the Calibri design and the two mixed Roman/Calibri designs.

Statistically significant differences were found among the different scales with the total score (p-value $=0.02$ ) and with both of the two mixed designs (Roman-Calibri and Calibri-Roman) with p-values of 0.012 and 0.018 respectively, as results of analysis of variance among the average scores of the scales for each design in Table 2 show. In all the significant cases, pair-wise comparisons were significant between the simplicity scale and all the other scales. The simplicity scale was given the highest average score in all the designs and the total. One can also note that with the craftsmanship scale, although not statistically significant, slightly higher average scores than the average scores of diversity and colorfulness scales were recorded in all cases.

Both of the simplicity scale and craftsmanship scale are related to the classical dimension of visual aesthetics, while the diversity and colorfulness are considered to be representatives of the expressive dimension of visual aesthetics [6]. The higher average scores given to the simplicity scale and the craftsmanship scale indicate that participants perceived the four deigns of the webpage as more classical than expressive. 
Table 1. Average questionnaire scores and results of analysis of variance

\begin{tabular}{|c|c|c|c|c|c|}
\hline Scale & Font Style & Average & $\begin{array}{l}\text { Standard } \\
\text { Deviation }\end{array}$ & $\mathbf{F}$ & P-value \\
\hline \multirow{5}{*}{ Simplicity } & Roman & 4.94 & 1.63 & \multirow{5}{*}{1.19} & \multirow{5}{*}{0.316} \\
\hline & Calibri & 4.76 & 1.53 & & \\
\hline & & & & & \\
\hline & Roman-Calibri & 4.79 & 1.61 & & \\
\hline & Calibri-Roman & 4.82 & 1.57 & & \\
\hline \multirow{5}{*}{ Diversity } & Roman & 4.45 & 1.57 & \multirow{5}{*}{0.39} & \multirow{5}{*}{0.754} \\
\hline & Calibri & 4.39 & 1.62 & & \\
\hline & & & & & \\
\hline & Roman-Calibri & 4.32 & 1.56 & & \\
\hline & Calibri-Roman & 4.42 & 1.61 & & \\
\hline \multirow{5}{*}{ Colorfulness } & Roman & 4.72 & 1.85 & \multirow{5}{*}{2.53} & \multirow{5}{*}{0.062} \\
\hline & Calibri & 4.41 & 1.81 & & \\
\hline & & & & & \\
\hline & Roman-Calibri & 4.28 & 1.85 & & \\
\hline & Calibri-Roman & 4.33 & 1.84 & & \\
\hline \multirow{5}{*}{ Craftsmanship } & Roman & 4.83 & 1.76 & \multirow{5}{*}{3.56} & \multirow{5}{*}{0.017} \\
\hline & Calibri & 4.52 & 1.75 & & \\
\hline & & & & & \\
\hline & Roman-Calibri & 4.47 & 1.68 & & \\
\hline & Calibri-Roman & 4.45 & 1.76 & & \\
\hline \multirow{5}{*}{ Total } & Roman & 4.73 & 1.58 & \multirow{5}{*}{2.88} & \multirow{5}{*}{0.040} \\
\hline & Calibri & 4.52 & 1.57 & & \\
\hline & & & & & \\
\hline & Roman-Calibri & 4.47 & 1.58 & & \\
\hline & Calibri-Roman & 4.51 & 1.60 & & \\
\hline
\end{tabular}


Table 2. Results of analysis of variance for scales

\begin{tabular}{|c|c|c|c|c|c|}
\hline Case & Scale & Average & $\begin{array}{l}\text { Standard } \\
\text { Deviation }\end{array}$ & $\mathbf{F}$ & P-value \\
\hline \multirow{5}{*}{ Roman } & Simplicity & 4.94 & 1.63 & \multirow{5}{*}{2.47} & \multirow{5}{*}{0.067} \\
\hline & Diversity & 4.45 & 1.57 & & \\
\hline & & & & & \\
\hline & Colorfulness & 4.72 & 1.85 & & \\
\hline & Craftsmanship & 4.83 & 1.76 & & \\
\hline \multirow{5}{*}{ Calibri } & Simplicity & 4.76 & 1.53 & \multirow{5}{*}{1.93} & \multirow{5}{*}{0.130} \\
\hline & Diversity & 4.39 & 1.62 & & \\
\hline & & & & & \\
\hline & Colorfulness & 4.41 & 1.81 & & \\
\hline & Craftsmanship & 4.52 & 1.75 & & \\
\hline \multirow{5}{*}{ Roman-Calibri } & Simplicity & 4.79 & 1.61 & \multirow{5}{*}{3.84} & \multirow{5}{*}{0.012} \\
\hline & Diversity & 4.32 & 1.56 & & \\
\hline & & & & & \\
\hline & Colorfulness & 4.28 & 1.85 & & \\
\hline & Craftsmanship & 4.47 & 1.68 & & \\
\hline \multirow{5}{*}{ Calibri-Roman } & Simplicity & 4.82 & 1.57 & \multirow{5}{*}{3.51} & \multirow{5}{*}{0.018} \\
\hline & Diversity & 4.42 & 1.61 & & \\
\hline & & & & & \\
\hline & Colorfulness & 4.33 & 1.84 & & \\
\hline & Craftsmanship & 4.45 & 1.76 & & \\
\hline \multirow{5}{*}{ Total } & Simplicity & 4.83 & 1.55 & \multirow{5}{*}{3.46} & \multirow{5}{*}{0.020} \\
\hline & Diversity & 4.39 & 1.53 & & \\
\hline & & & & & \\
\hline & Colorfulness & 4.43 & 1.74 & & \\
\hline & Craftsmanship & 4.57 & 1.68 & & \\
\hline
\end{tabular}




\section{Conclusions}

This study was an extension of an earlier study [1], the purpose of the current study is to investigate how using a mixture of different font styles and font types in the same webpage (compared to the single styles and types used in the earlier study) would affect perception of visual aesthetics of the webpage design. Four webpage designs were compared; the two designs used in the earlier study (one with the Time News Roman font and one with the Calibri font), and another two designs containing a mixture of both fonts.

Analysis of results supports the findings of the earlier study; the "serif" style (represented by the Time New Roman design) was perceived as having better visual aesthetics than the "sans-serif" style (represented by the Calibri design). Furthermore analysis of results also showed that the Times New Roman was also perceived as having better visual aesthetics than both of the mixed designs; i. e. mixing both styles in the same page (serif and san-serif) didn't improve perception of visual aesthetics.

However, these results were only significant on the overall perception of visual aesthetics (the overall questionnaire score) and on the craftsmanship scale; it wasn't significant in each of the other three parts of the questionnaire (representing the facets of visual aesthetics).

As in the earlier study, results, here too, showed that participants perceived the design as more classical than expressive. It would be interesting to see if the above results (regarding font styles) would hold in cases of more aesthetically expressive designs.

Finally, the issue of a possible role of the context of use on perception of visual aesthetics of webpage design and how that might have affected the results of the current study need to be addressed in future research. Findings of several previous studies have indicated possible effects of context of use (serious context vs. funny and pleasurable context) on perception of visual aesthetics of webpage design [3 and 9]. The context of use in the current study can be considered as a more serious one. It would be interested to see if outcomes of the test would change in case of a more pleasurable context.

\section{References}

1. Altaboli, A.: Investigating the effects of font styles on perceived visual aesthetics of website interface design. In: Kurosu, M. (ed.) Human-Computer Interaction, Part I, HCII 2013. LNCS, vol. 8004, pp. 549-554. Springer, Heidelberg (2013)

2. Bernard, M., Chaparro, B., Mills, M., Halcomb, C.: Comparing the effects of text size and format on the readability of computer-displayed Times New Roman and Arial text. Int. J. Human-Computer Studies 59, 823-835 (2003)

3. De Angeli, A., Sutcliffe, A., Hartmann, J.: Interaction, usability and aesthetics: what influences users' preferences? In: Proceedings of the Sixth ACM Conference on Designing Interactive Systems, PA (June 2006)

4. Dix, A., Finlay, D., Abowd, G., Beale, R.: Human-Computer Interaction, 3rd edn. Pearson Education (2004) 
5. Ling, J., Van Schaik, P.: The influence of font type and line length on visual search and information retrieval in web pages. Int. J. Human-Computer Studies 64, 395-404 (2006)

6. Laviea, T., Tractinsky, N.: Assessing dimensions of perceived visual aesthetics of web sites. Int. J. Human-Computer Studies 60, 269-298 (2004)

7. Moshagen, M., Thielsch, M.T.: Facets of visual aesthetics. Int. J. Hum.-Comput. Stud. 68(10), 689-709 (2010)

8. Sheedy, J., Subbaram, M., Zimmerman, A., Hayes, J.: Text Legibility and the Letter Superiority Effect. Human Factors 47(4), 797-815 (2005)

9. Van Schaik, P., Ling, J.: The role of context in perceptions of the aesthetics of web pages over time. Int. J. Human-Computer Studies 67, 79-89 (2009) 